NASA TECHNICAL MEMORANDU M

$n$
$\frac{n}{\dot{n}}$
$\Sigma$
$\Sigma$
$\sum$
$\sum$

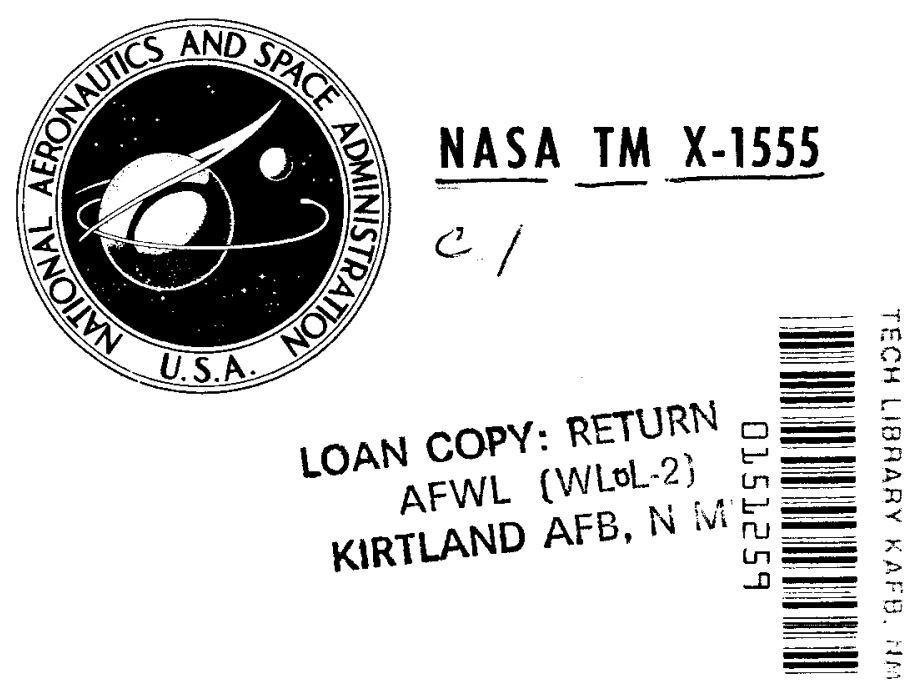

\title{
CRYOGENIC POSITIVE
} EXPULSION BLADDERS

by Raymond F. Lark

Lewis Research Center

Cleveland, Obio

NATIONAL AERONAUTICS AND SPACE ADMINISTRATION - WASHINGTON, D. C. - APRIL 1968 


\title{
CRYOGENIC POSITIVE EXPULSION BLADDERS
}

\author{
By Raymond F. Lark
}

Lewis Research Center

Cleveland, Ohio

\section{NATIONAL AERONAUTICS AND SPACE ADMINISTRATION}

For sale by the Clearinghouse for Federal Scientific and Technical Information Springfield, Virginia 22151 - CFSTI price $\$ 3.00$ 


\title{
CRYOGENIC POSITIVE EXPULSION BLADDERS*
}

\author{
by Raymond F. Lark \\ Lewis Research Center
}

\section{SUMMARY}

Lewis Research Center in-house and contractual experimental programs were conducted to determine the cryogenic flexibility of single and multiple plies of thin polymeric films at $-320^{\circ}$ and $-423^{\circ} \mathrm{F}\left(77^{\circ}\right.$ and $\left.20^{\circ} \mathrm{K}\right)$. Results of cryogenic flexibility or "twistflex" testing showed that thin Mylar films, that is, $0.5 \mathrm{mil}(0.0013 \mathrm{~cm})$ and less, are the most flexible of the films tested. The relations between cryogenic cycle-life and film thickness and also for the number of plies of Mylar film are reported at $-320^{\circ}$ and $-423^{\circ} \mathrm{F}$ $\left(77^{\circ}\right.$ and $\left.20^{\circ} \mathrm{K}\right)$. "Twist-flex" cycle life of $0.25-\mathrm{mil}(0.00063-\mathrm{cm})$ Mylar C samples at $-423^{\circ} \mathrm{F}\left(20^{\circ} \mathrm{K}\right)$ range from 20 to 400 cycles, for 1 and 10 plies respectively.

Results of contractual testing of spherical multi-ply Mylar, Kapton, and polyethylene film bladders, 12 inches outside diameter $(30.5 \mathrm{~cm})$, are summarized. Bladder material combinations showing the lowest helium gas porosity after 25 liquid hydrogen positive expulsion cycles are:

(1) Twelve plies of $0.15-\mathrm{mil}(0.00038-\mathrm{cm})$ Mylar C in combination with $20 \mathrm{plies}$ of 0.1 -mil $(0.00025-\mathrm{cm})$ polyethylene film

(2) Ten plies of $0.5-$ mil Kapton in combination with three plies of $2-\mathrm{mil}(0.005-\mathrm{cm})$ Nomex-Nylon paper.

\section{INTRODUCTION}

As more complex space missions are planned, new requirements become essential for space vehicle design. One of the areas of major interest is the study and development of methods for transfer or ejection of cryogenic propellants under a zero-gravity environment to a point of usage.

An essentially zero-gravity environment is produced on a vehicle and its component

*Material from this report was presented at the First Annual Cryogenic Polymers Conference sponsored by Case Institute of Technology and NASA, Cleveland, Ohio, April 25-27, 1967. 
parts during certain portions of its space flight. The relative positions that a fluid and its vapor will occupy in its storage tank during zero-gravity have been extensively investigated (ref. 1). Propellant tanks can be designed to exploit the known properties of surface tension forces and to orient the fluid and its vapor over the appropriate discharge ports by use of surface tension stand pipes and screens. However, adverse accelerations, such as lateral movements caused by the vehicle attitude control system, may cause the discharge port to be uncovered.

The positive expulsion concept of fluid delivery is applicable under a wide range of gravity conditions. The term "positive expulsion" as applied to bladders is defined as the ejection or discharge of a fluid contained within the bladder by means of an externally applied force (usually gas pressure). Basic approaches to positive expulsion have included the use of elastomeric bladders and diaphragms, and metal bellows or pistons. A flexible bladder or diaphragm remains the predominant device in current use for positive expulsion of most "earth storable" propellants. These are shown schematically in figure 1. Internal wrinkling and folding of the bladder or diaphragm occurs during the expulsion cycle. At earth ambient temperatures, such material wrinkling has resulted in few material flexibility problems since elastomeric-like materials may be effectively used. At cryogenic temperatures, such as $-423^{\circ} \mathrm{F}\left(20^{\circ} \mathrm{K}\right)$ for liquid hydrogen, polymeric materials no longer exhibit elastomeric (i. e., rubber-like) behavior. Most polymeric materials become extremely brittle and lack sufficient extensibility to withstand extensive wrinkling and folding without fracturing. Several programs have accordingly been initiated to investigate the use of flexible polymeric materials for cryogenic expulsion bladder applications.

The purpose of this report is to summarize Lewis Research Center's in-house and contractual testing data for two promising polymeric expulsion bladder barrier films (Mylar and Kapton) and two substrate materials (polyethylene film and Nomex-Nylon paper). Research done to evaluate the concept of using substrate materials between barrier plies for increasing cryogenic cycle life is discussed. (It was anticipated that "free floating" flexible substrate plies would increase the bend radii of films during threecorner folding and hence extend cryogenic cycle life of the composite films.)

Also included are data which show the effect of Mylar film thickness on cryogenic "flexibility" (as determined by the twist-flex test method) at $-320^{\circ} \mathrm{F}\left(77^{\circ} \mathrm{K}\right.$ ) and the improvement in twist-flex cycle life at $-320^{\circ}$ and $-423^{\circ} \mathrm{F}\left(77^{\circ}\right.$ and $\left.20^{\circ} \mathrm{K}\right)$ by using multiplies of Mylar film.

\section{EXPULSION REQUIREMENTS}

Although complete definitized cryogenic expulsion system requirements are depend- 
ent on specific application requirements, certain general requirements can be listed as follows. Expulsion devices should:

(1) Have minimum weight

(2) Have low values of gas porosities for the expulsion membrane (Minimum values are not presently defined and accordingly present goals are to minimize porosity.)

(3) Be capable of being fabricated by practical and economical techniques

(4) Use commercially available materials

(5) Utilize barrier materials that remain flexible at cryogenic temperature and resist failures caused by rolling three-corner folds (formed by folds and wrinkles during expulsion cycling) (Fig. 2 schematically shows the severe elongation and stressing which is imposed on materials during three-corner folding.)

(6) Have multicycling capability to permit preflight testing Typical polymeric bladder material failures are illustrated in figure 3.

\section{TEST APPARATUS}

\section{Flexibility Testing}

Since it was not considered economical to screen polymeric materials for cryogenic flexibility properties by building and testing expulsion bladders, a test method (ref. 2) was developed to simulate wrinkling and folding conditions encountered during bladder cycling. In addition, the test method uses low-cost samples of film in the form of flat sheets 4 inches in width and 11 inches in length. The equipment used for this testing is called the "twist-flex" tester and is illustrated in figure 4 . The sample is mounted on circular end plates and held in place with clamps as shown in figure 5. The motion imparted to the sample during testing is shown schematically in figure 6 .

Early testing of films via the twist-flex tester evaluated material performance by the visual "pin hole failure criteria." Film samples were cycled until failure, such as pin holes and tears, was detected by visual observation. (The data obtained by this method had considerable scatter.) The so-called "water bubble" failure criterion was used for the majority of polymeric film samples tested at Lewis Research Center. The film samples were twist-flexed both individually and in multi-ply form for a varying number of cycles. Upon completion of cycling, the sample was placed in a gas porosity testing fixture and pressurized with helium gas at $1 \mathrm{psig}\left(0.69 \mathrm{~N} / \mathrm{cm}^{2}\right)$ from beneath the sample. The upper surface of the sample was covered with a layer of water $1 / 4-$ inch $(0.6 \mathrm{~cm})$ deep. Leakage of gas through film areas having high porosity, caused by extensive 
stressing during twist-flex cycling, was observed visually. In order to establish a failure level, the following procedure was used:

(1) When the flex-cycle life of a sample was unknown, samples were cycled in the cryogen at intervals of $10,25,50$, or 100 cyles and withdrawn for porosity testing. The same film samples after being tested for porosity are not reinstalled on the testing fixture. (Experience had shown that reinstallation could not be done in the exact former manner and flexing could occur at new "'bending points. ")

(2) When bubbles just become visible after a minimum pressurization period of 3 minutes, the so-called "flex-life" of a sample was considered to have been reached.

(3) A minimum of 12 additional samples were then flex-cycled at or near this value. The flex life was found to be repeatable within \pm 10 percent of this threshold value.

\section{Bladder Porosity Testing}

A method for helium gas porosity and leak testing of bladders was developed by the Beech Aircraft Corporation under Contract NAS3-6288. This testing method was used during fabrication to test the completed bladder as well as individual bladder plies for leakage. In addition, the testing method was also used to test bladders for leakage after cryogenic cycle-testing. A schematic diagram of this testing apparatus is shown on figure 7. An individual ply or the completed bladder is mounted inside a glass bell jar equipped with a tight fitting cover. Helium gas is introduced into the bladder until 1-psig $\left(0.6-\mathrm{N} / \mathrm{cm}^{2}\right)$ pressure is established. The volume of gas which permeates through the bladder material is collected in a burette by a fluid displacement technique. The porosity per unit time is calculated by dividing the gas volume by the elapsed time. All tests for porosity were conducted at $75^{\circ} \mathrm{F}\left(276^{\circ} \mathrm{K}\right)$.

\section{Cryogenic Expulsion Testing}

A schematic of the expulsion facility for the liquid hydrogen testing of bladders by Beech Aircraft Corporation, under NAS3-6288, is shown in figure 8. This facility has the capability of testing by either "outward" or "inward" expulsion. Liquid hydrogen is conducted via vacuum jacketed piping from a storage dewar. Gaseous helium for pressurization of the bladder test tank is prechilled by means of a heat exchanger mounted in the storage dewar. 


\title{
RESULTS AND DISCUSSION
}

\author{
Single Ply Samples
}

This Lewis Research Center investigation was primarily limited to commercially available films and film composites, and included only known materials which were available in film form. Extensive flexibility screening was performed initially at the temperature of $-320^{\circ} \mathrm{F}\left(77^{\circ} \mathrm{K}\right)$, and finally at $-423^{\circ} \mathrm{F}\left(20^{\circ} \mathrm{K}\right)$. Films such as Mylar and Kapton which demonstrated high cryogenic flexibility were examined in more detail to establish the relation between twist-flex cycle life and film thickness.

The polymer showing the most promise was poly (ethylene terepthalate). A biaxially oriented film of this polymer is known commercially as Mylar.

Figure 9 shows the relation of (single ply) Mylar film thickness to cryogenic cycle life at $-320^{\circ} \mathrm{F}\left(77^{\circ} \mathrm{K}\right)$. It can be seen that the $1 / 4-\mathrm{mil}(0.00063-\mathrm{cm})$ film showed the highest twist-flex cycle life of the thicknesses tested. A comparison of twist-flex testing values for 1/2-mil type $A$ and $C$ Mylar in single film plies, shown in figure 9 , also shows that type $\mathrm{C}$ film is more flexible. Type A film is available only in thicknesses down to $1 / 2$ mil while type $C$ is available in thicknesses of $1 / 2 \mathrm{mil}$ and less. In addition to type $C$ being more flexible and available in thinner films, testing of type $C$ film samples yielded less data scatter than type A and appeared to be more uniform in quality.

\section{Multi-Ply Samples}

It was believed that porosity of polymeric bladder materials to helium gas could be decreased by using thin barrier films in a multi-ply configuration. In addition, it was also believed that multiple-thin barrier films used alone or in combination with substrate plies would greatly increase cryogenic cycle-life performance. The poor twist-flex cycling performance of relatively thick Mylar films precluded using a single-ply bladder for attainment of minimum values of helium gas porosity.

Many thin films of material used together would also result in an overall increase in the "bend radii" of this composite material during folding and wrinkling. A corresponding increase in cryogenic cycling performance should be achieved. Thin plies of barrier films such as Mylar, are however, very susceptible to tearing. Therefore, the concept of using flexible substrate materials such as fabrics and felt between barrier plies to inhibit tearing tendencies was evolved.

Twist-flex data for multiple unbonded plies of Mylar $C$ as well as several data points for barrier film/substrate combinations are shown on figure 10. Again, it can be seen that samples made of $1 / 4-$ mil $(0.00063-\mathrm{cm})$ Mylar film showed the highest cycle life. 
Also, the data shows that cyclic life at $-423^{\circ} \mathrm{F}\left(20^{\circ} \mathrm{K}\right)$ is substantially lower than at $-320^{\circ} \mathrm{F}\left(77^{\circ} \mathrm{K}\right)$. A data point showing the twist-flex performance of two plies of $1 / 2-\mathrm{mil}$ (0.00125-cm) Mylar and one ply of Dacron fabric has been plotted along the "plain" $1 / 2$-mil $(0.00125-\mathrm{cm})$ Mylar curve for the $-320^{\circ} \mathrm{F}\left(77^{\circ} \mathrm{K}\right)$ testing on figure 10. A negligible increase in performance can be seen. A data point showing the twist-flex performance of five plies of 1/4-mil $(0.00063-\mathrm{cm})$ Mylar film and four plies of Dacron fabric has also been plotted along the "plain" $1 / 4-\mathrm{mil}(0.00063-\mathrm{cm})$ Mylar curve for testing at $-320^{\circ} \mathrm{F}\left(77^{\circ} \mathrm{K}\right)$. A somewhat greater increase in performance is noted.

During the cryogenic twist-flex testing of multi-ply polymeric samples of either Mylar or Kapton at Lewis, it was noted that diffusion of the cryogens, that is, liquid nitrogen or liquid hydrogen, between the plies occurred while the samples were immersed. Subsequent removal of the samples from the cryogen resulted in inflation of the plies caused by evaporation of the cryogen. The Beech Aircraft Corporation was directed to evaluate this problem more fully under Contract NAS3-6288. It was found that interply inflation would occur in twist-flex samples which were simply immersed in the cryogen (liquid hydrogen) for a period of time up to 30 minutes and then quickly withdrawn. The appearance of both flat and cylindrical-type specimens before and after immersion is shown in figure 11. There did not appear to be a well defined correlation between the degree of inflation against the number of cycles the samples were tested nor for varying times of immersion in the case of the static immersion tests.

On a basis of measuring thicknesses of inflated twist-flex samples (at ambient temperatures), however, Kapton film did show more serious interply inflation tendencies than Mylar.

A possible explanation for interply inflation is that the diffusivity of a cryogenic liquid through a polymeric film (at the temperature of the cryogen) is higher than the diffusivity rate of the vapor through the film at ambient temperatures. There is also a cryopumping action caused by the atmosphere contained between the plies shrinking upon cooldown and occupying less volume at low temperatures, hence, resulting in a reduced interply pressure. This reduced interply pressure would then tend to come to an equilibrium with the pressure of the surrounding cryogen by passage of the cryogen into the interply area. The high liquid-to-gas expansion ratio (784 for liquid hydrogen) would result in the evaporation of an insignificant of volume of liquid to a large volume of gas at ambient temperatures. In some test specimens (at Lewis) inflation was sufficient to cause rupture of the samples.

\section{Bladder Fabrication Techniques}

In addition to cryogenic flexibility and low porosity considerations, a polymeric film 
should be amenable to processing into the shape of bladders or diaphragms. Ideally, a bladder should be a seamless structure to achieve maximum reliability and uniformity, or, at most, have a maximum of one circumferential seam for the joining of two hemispherical film shapes. Considerable effort has been expended at Lew is and on a contractual effort (NAS3-6288) to evaluate the potential of Mylar films shaped by vacuum and/or pressure forming. The potential for decreasing the cost of bladders appeared high due to significantly lower labor requirements compared to a bladder constructed from gore segments.

The Boeing Company has developed a process for stretch forming 1/4-mil (0.00063$\mathrm{cm}$ ) Mylar film into wrinkle-free hemispheres. A number of hemispheres made by this process were procured and tested by Beech Aircraft Corporation under Lewis Contract NAS3-6288. Hemispheres were cut into twist-flex samples and tested for porosity and twist-flex life in liquid hydrogen. High values for porosity and low cryogenic cycle life ruled out the use of this material for bladders in the program summarized here. Subsequent porosity testing by Lewis of stretch-formed Kapton films for Boeing Company under Contract NAS3-7952 also indicated high porosity values. Accordingly, the decision was made to use the gore method for construction of bladders in both programs. In this method "Orange-peel" or gore segments cut from flat film are joined by use of adhesives.

Prior to fabrication of bladders in Beech's contract, an extensive evaluation was conducted of seaming methods for joining the most flexible and promising types of film, that is, thin films (on the order of $1 / 2 \mathrm{mil}(0.00125 \mathrm{~cm}$ ) or less in thickness) of polyethylene (for use as a substrate ply), Mylar and Kapton. Samples of these films were made up into twist-flex specimens with variations in the type of seams, that is, butt or lap, thickness of adhesive (previously screened at Lewis and found to be flexible at cryo temperatures), and seam width. Test results confirmed previous experience by Lewis which indicated that either the lap or butt-type of seam was acceptable provided that the adhesive was applied in a thickness no greater than the film being bonded. The type of adhesive found most acceptable for bladders was a thermoplastic polyester type manufactured by the G. T. Schjeldahl Company. The adhesive in liquid and tape form is designed "GT-100." The tape was used for all lap-type seams. A Mylar C film tape coated on one side with GT-100 was used for all butt-type seams.

Joining of Mylar C films by ultrasonic welding was also evaluated under Contract NAS3-6288. This technique did not prove feasible for the sealing of single plies of $1 / 4-\mathrm{mil}(0.00063-\mathrm{cm})$ film.

Testing experience in the various referenced programs have all indicated that anticipated problems with seams in twist-flex and bladder specimens have not materialized. It appears that the bulky nature of seams forces films wrinkling and folding to occur in 
the unseamed portion of test specimens. No known gross bladder failures tested in Contract NAS3-6288 have been traced to seams.

\section{Bladder Testing}

On the basis of Lewis and Beech cryogenic twist-flex testing of single and multiple plies of film, the contractor was directed to construct and test spherical bladders on NAS3-6288 made from the materials shown in table I.

Two bladders of each type were cycle-tested in liquid hydrogen up to a maximum of 25 cycles. The conventional method of bladder expulsion, that is, inward expulsion was specified. This method is commonly used for the earth storable-type propellants. Bladders were tested for helium gas porosity at ambient temperatures prior to the first cycle and after each fifth cycle.

A progressive increase was found in gas porosity with the number of cycles tested. Interply inflation proved to be a serious hindrance to the successful testing of the bladders while using inward expulsion. Interply inflation was observed immediately after introduction of the cryogen into the interior of the bladder. The cryogen initially would start chilling the bottom area of the bladder. Diffusion of the liquid cryogen would then take place through the inner plies of the bladder near the bottom. Subsequent evaporation of the diffused cryogen by warm portions of the bladder plies then took place which resulted in progressive ply inflation. Inflation continued until much of the volume of the test tank was occupied with inflated plies which prevented filling of the bladder. After experiencing filling difficulties by inward expulsion, a portion of the cycles on several bladders were performed using an outward expulsion technique, that is, cryogen on the exterior of the bladder. The effect of interply inflation was not observed for these cycles due to a lack of an appreciable temperature gradient across the bladder plies (i. e., during outward expulsion, the bladder is not in contact with the relatively warm tank walls as is the case for inward expulsion).

Bladder testing data indicated that all bladders showed at least some incipient material failures after five liquid hydrogen cycles. Porosity measurements at five cycles and at the maximum number of liquid hydrogen cycles tested are as follows: 


\begin{tabular}{|c|c|c|}
\hline Bladder types & $\begin{array}{c}\text { Porosity values, } \\
\mathrm{cm}^{3} / \mathrm{min}\end{array}$ & Liquid hydrogen cycles \\
\hline 1 & $14 / 5$ & $5800 / 25$ \\
\hline 1 & $10 / 5$ & $18 / 25$ \\
\hline 2 & $500 / 5$ & $\overline{\ldots-\ldots-}$ \\
\hline 2 & $10 / 5$ & $3300 / 25$ \\
\hline 3 & $300 / 5$ & $28000 / 15$ \\
\hline 3 & $39 / 5$ & $17000 / 25$ \\
\hline 4 & $700 / 5$ & $28000 / 25$ \\
\hline 4 & $31 / 5$ & $428 / 25$ \\
\hline 5 & $13 / 5$ & $80 / 25$ \\
\hline 5 & $2 / 5$, & $240 / 25$ \\
\hline
\end{tabular}

Type 5 (Kapton) bladders yielded the lowest values of porosity up to 25 liquid hydrogen cycles and also the most consistent performance. The most severe interply inflation difficulties were experienced with these bladders during inward expulsion. Filling and expulsion operations were, however, excellent with outward expulsion.

The lowest value for helium gas porosity after 25 liquid hydrogen cycles was achieved by one of the type 1 bladders. Much of the test data scatter for the other bladder of this type, as well as other bladders, however, can be attributed to random material failures (i.e., splits, tears, pinholes, and porous areas) originating near the stem attachment and polar cap areas of the bladder. It is believed that overstressing and wrinkling of the bladder material was more severe in these areas. Some of these failures could also be attributed to overstressing of the bladder material during insertion into and removal of the bladder from the expulsion tank for ambient temperature porosity measurements.

\section{SUMMARY OF RESULTS}

The results of the bladder development programs can be summarized as follows:

1. Combinations of flexible polymeric films have been successfully developed. Thin films of Mylar and Kapton retain sufficient flexibility and toughness, at the temperature of liquid hydrogen, to be useful for construction of cryogenic expulsion bladders.

2. Bladder fabrication techniques for joining flat gore film segments into spherical bladders have been successfully developed.

3. The use of multiply unbonded and independent plies of films increases the cryogenic cycle life performance of bladder materials. 
4. The use of flexible substrates between bladder plies to serve as ''bend radii increasers" or cycle-life extenders has not been established conclusively.

5. The optimum number of plies for a bladder in liquid hydrogen service has not been established. It would appear that substantial increases in cryogenic cycling performance can be obtained by increasing the number of plies beyond that evaluated in these programs. The upper limit to the number of plies would be very likely limited by such practical considerations as bladder weight, decreased volumetric expulsion efficiencies due to physical bladder bulkiness, and fabrication costs.

6. Bladder materials which rated lowest in helium gas porosity (at ambient temperature) after 25 liquid hydrogen cycles were Mylar/MERFAB and Kapton/Nomex-nylon paper combinations.

7. The utilization of thin multi-ply polymeric film bladders is particularly promising where, (a) some diffusion of the pressurant gas into the propellant can be tolerated and (b) where interply inflation can be controlled as is the case for outward expulsion.

\section{Lewis Research Center,}

National Aeronautics and Space Administration, Cleveland, Ohio, January 5, 1968, 124-08-08-26-22.

\section{REFERENCES}

1. Petrash, Donald A. ; Nussle, Ralph C. ; and Otto, Edward W. : Effect of Contact Angle and Tank Geometry on the Configuration of the Liquid-Vapor Interface During Weightlessness. NASA TN D-2075, 1963.

2. Pope, D. H.; and Killian, W. R. : Positive Expulsion of Cryogenic Liquids. Eng. Rep. No. 14180 (NASA CR-55898), Beech Aircraft Corp. , June 1963. 
TABLE I. - POLYMERIC FILM BLADDERS

[Nominal diameter, 12 in. $(30.5 \mathrm{~cm})$. ]

\begin{tabular}{|c|c|c|c|c|c|c|c|c|c|c|}
\hline \multirow{3}{*}{$\begin{array}{l}\text { Bladder } \\
\text { type }\end{array}$} & \multicolumn{4}{|c|}{ Barrier } & \multicolumn{6}{|c|}{ Substrate } \\
\hline & \multirow[t]{2}{*}{ Material } & \multicolumn{2}{|c|}{ Thickness } & \multirow{2}{*}{$\begin{array}{l}\text { Number } \\
\text { of plies }\end{array}$} & \multirow[t]{2}{*}{ Material } & \multicolumn{2}{|c|}{ Thickness } & \multicolumn{2}{|c|}{ Weight } & \multirow{2}{*}{$\begin{array}{l}\text { Number } \\
\text { of plies }\end{array}$} \\
\hline & & mils & $\mathrm{cm}$ & & & mils & $\mathrm{cm}$ & $\mathrm{oz} / \mathrm{yd}^{2}$ & $\mathrm{~g} / \mathrm{cm}^{2}$ & \\
\hline 1 & Mylar C & $|0.15|$ & 0.00038 & 12 & $\operatorname{Merfab}^{a}$ & -- & ----- & --- & ---- & 10 \\
\hline 2 & Mylar C & .25 & .00063 & 10 & Nomex-Nylon paper ${ }^{b}$ & 2 & 0.0051 & -- & ---- & 3 \\
\hline 3 & Mylar C & .25 & .00063 & 10 & Dacron fabric & -- & ----- & 2.2 & 0.008 & 3 \\
\hline 4 & Mylar C & .25 & .00063 & 10 & - & -- & $-\cdots-$ & --- & $-\ldots$ & -- \\
\hline 5 & Kapton & .50 & .00125 & 10 & Nomex-Nylon paper ${ }^{b}$ & 2 & .0051 & -- & ---- & 3 \\
\hline
\end{tabular}

${ }^{a}$ Sandwich laminate of two plies of $0.1-\mathrm{mil}(0.00025-\mathrm{cm})$ polyethylene film with interply reinforcement of Dacron fibers (product of Sea Space Systems, Inc.).

${ }^{b}$ Polyamide fibrous material (product of DuPont). 
Hemispherical-

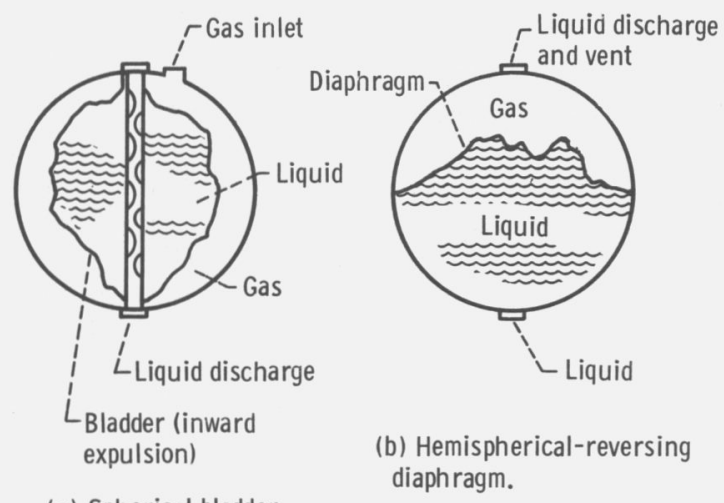

(a) Spherical bladder.

Figure 1. - Positive expulsion devices.

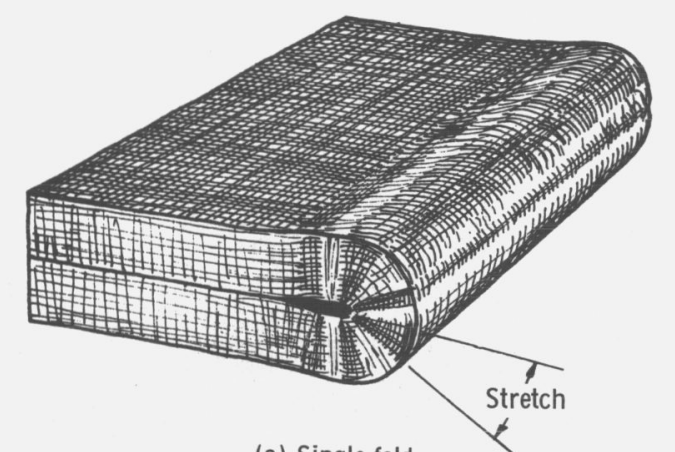

(a) Single fold.

Severe stretch

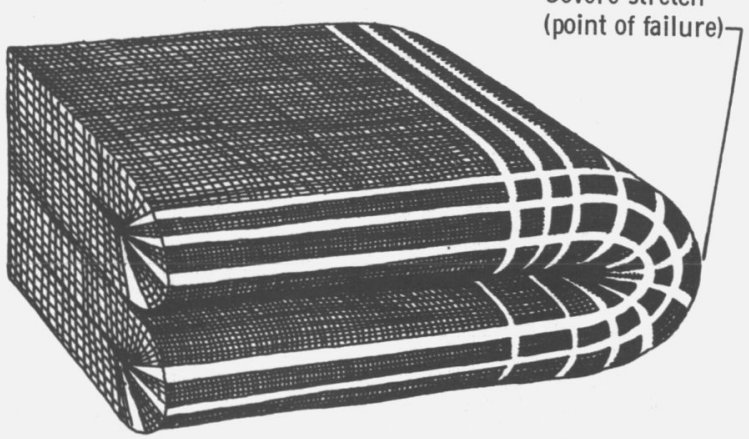

(b) Three-corner fold.

Figure 2. - Single and three-corner folds. 


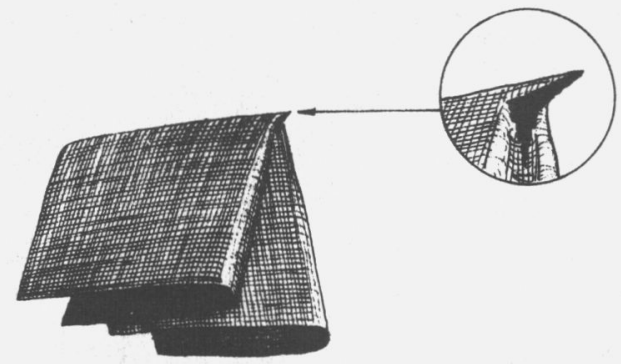

(a) External tongue-type tear.

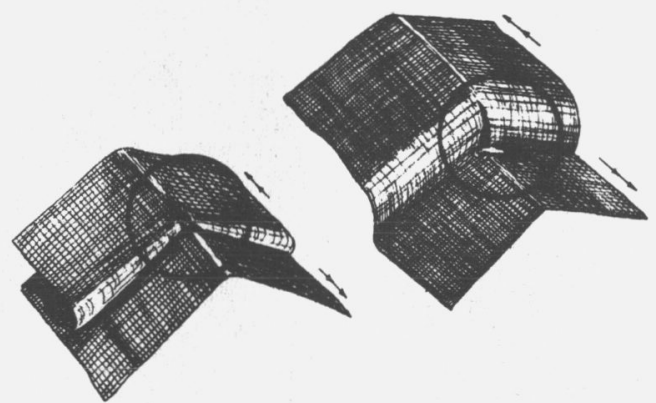

(b) Internal tongue-type tear.

Figure 3. - Material failures caused by rolling three-corner folds.

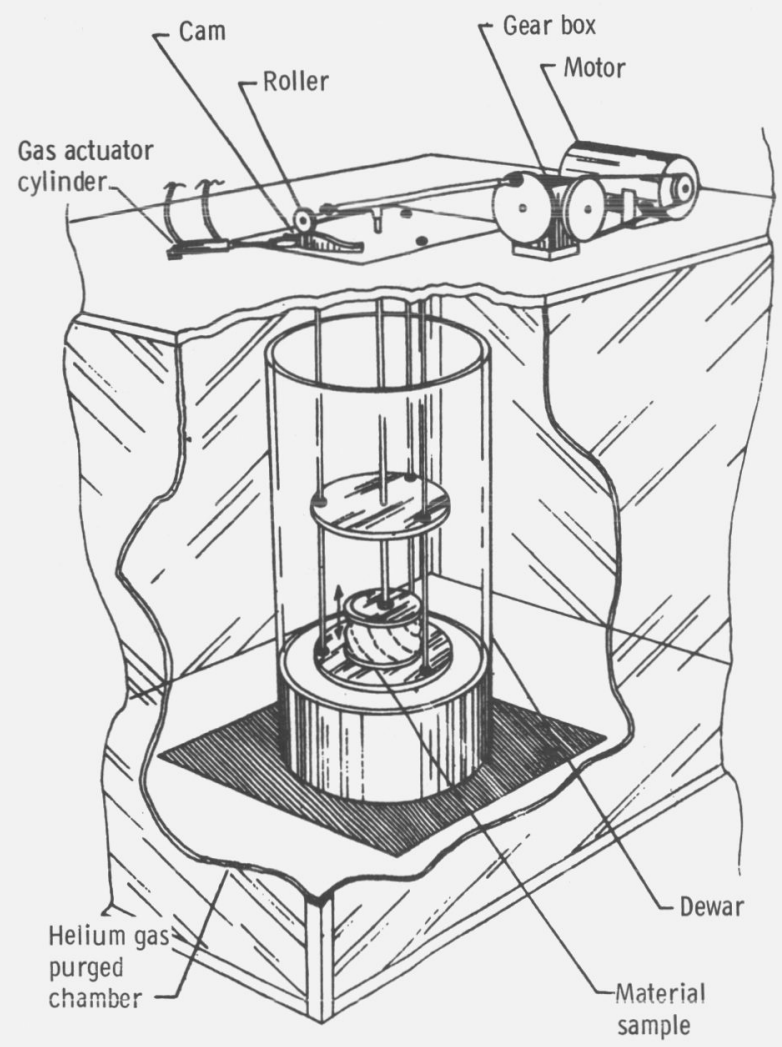

Figure 4. - Twist-flex film-testing apparatus. 


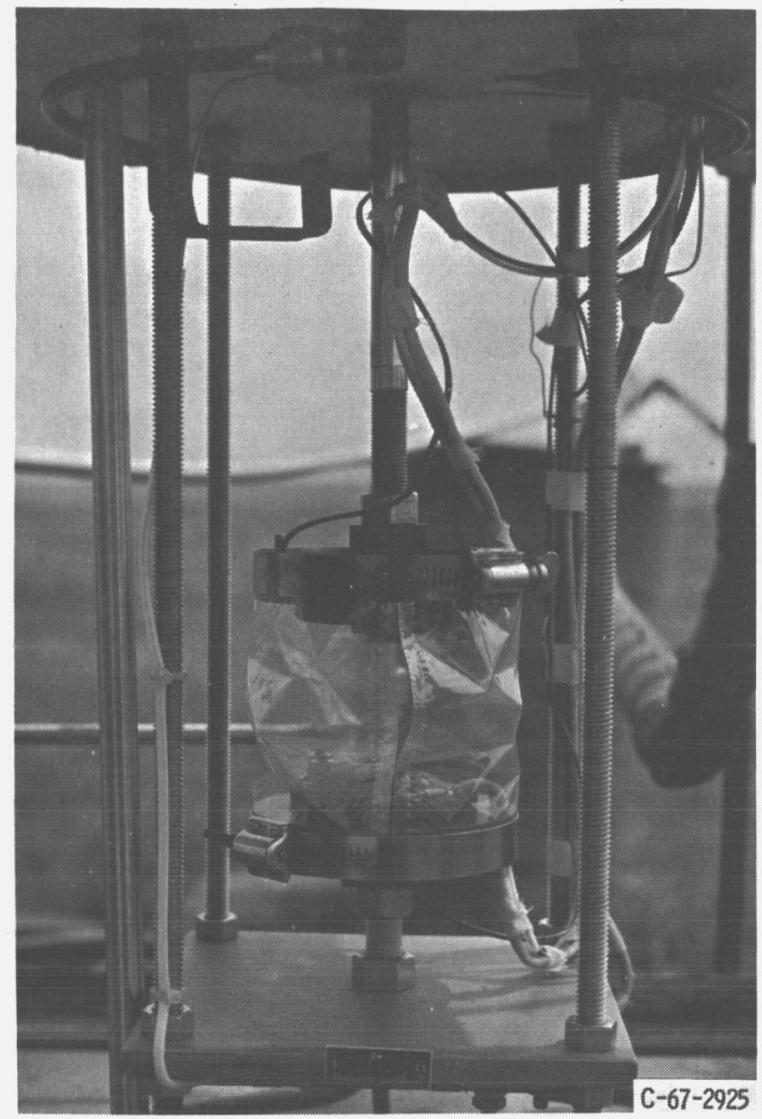

Figure 5. - Twist-flex sample installed on end plates.

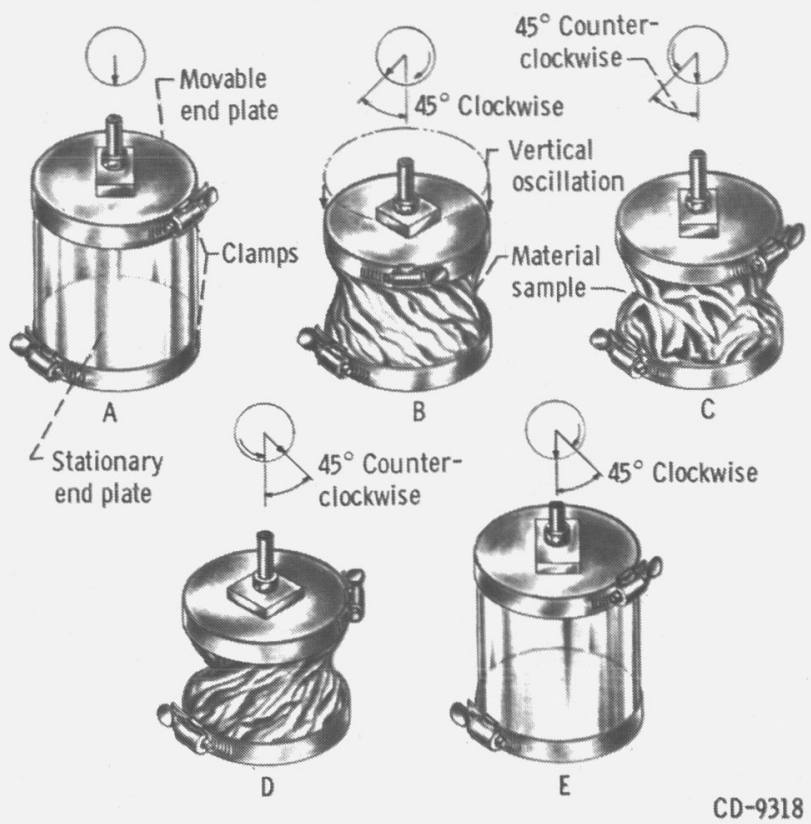

Figure 6. - Twist-flex testing cycle. 


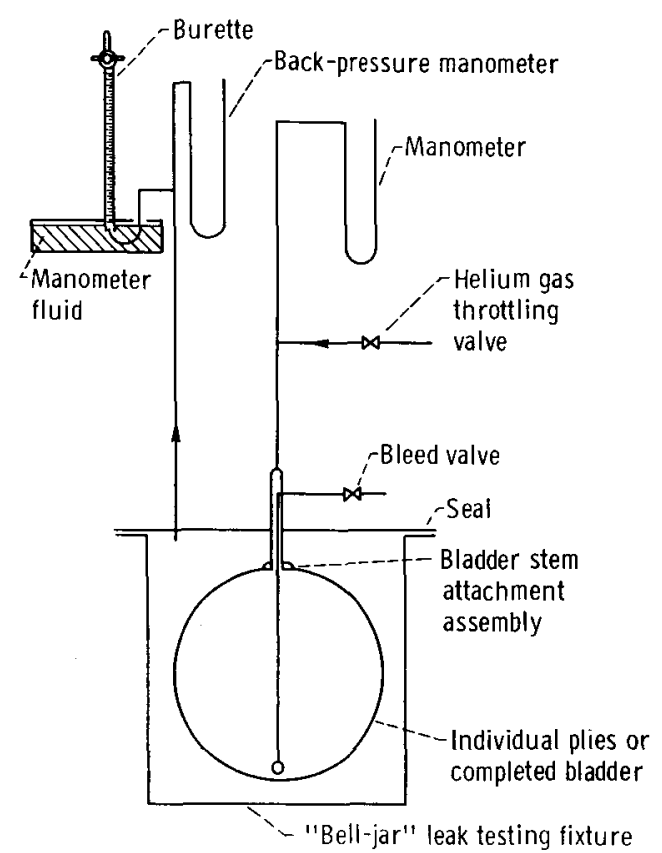

Figure 7. - Bladder and bladder-ply leak checking.

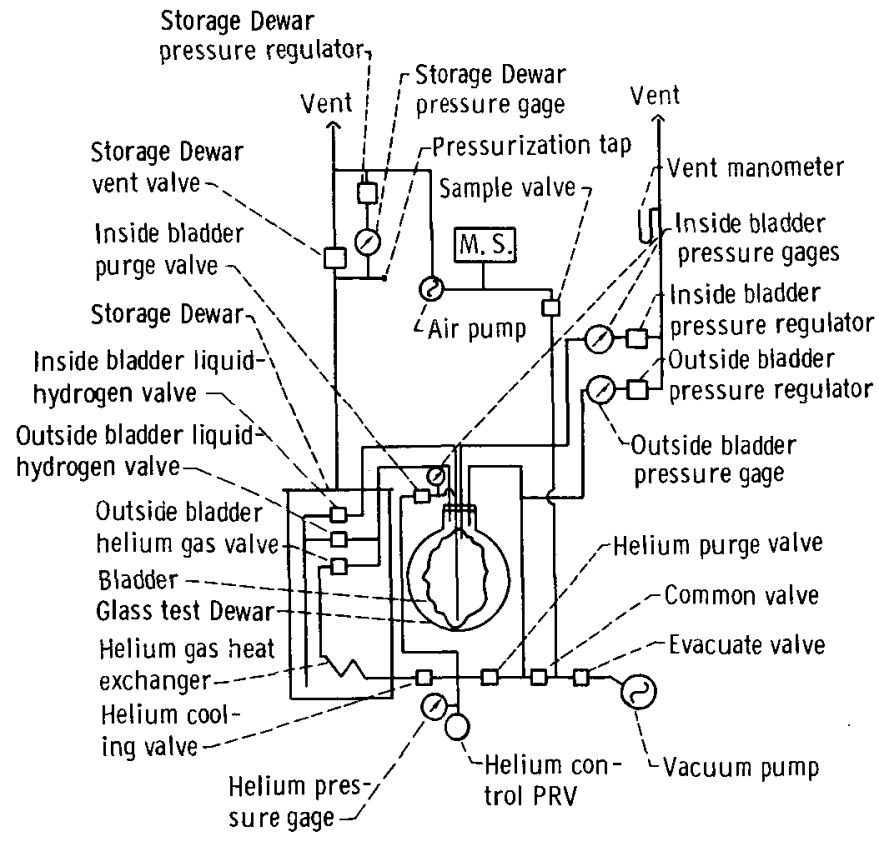

Figure 8. - Expulsion test system. 


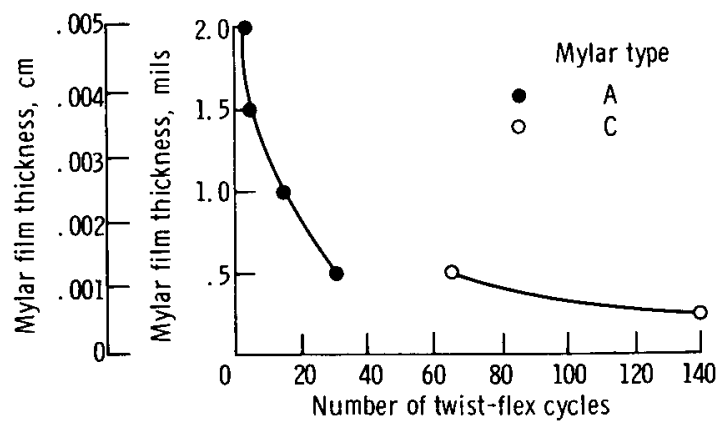

Figure 9. - Relation of single-ply Mylar film thickness to twist-flex cycle life. Bubblefailure porosity testing method temperature, $-320^{\circ} \mathrm{F}\left(77^{\circ} \mathrm{K}\right)$.

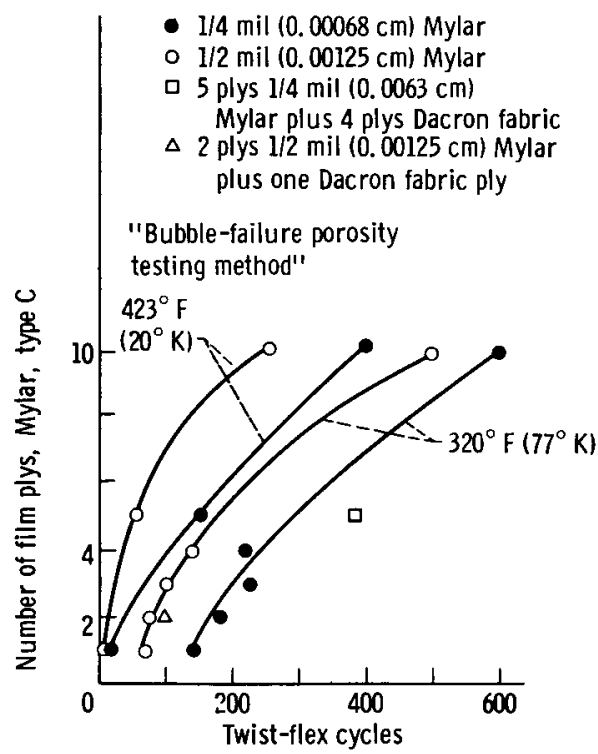

Figure 10. - Relation of number of Mylar C film plies to twist-flex cycle life. 

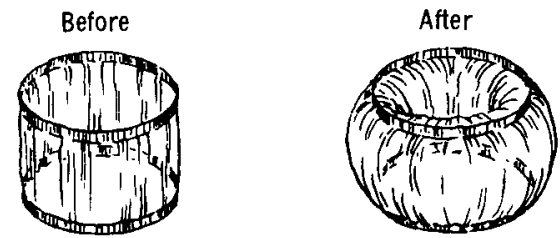

(a) Side view of cylindrical sample.
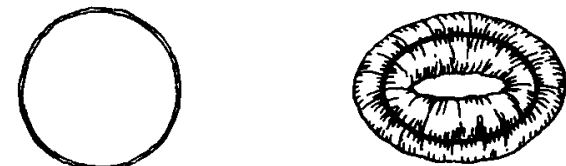

(b) Top view of cylindrical sample.

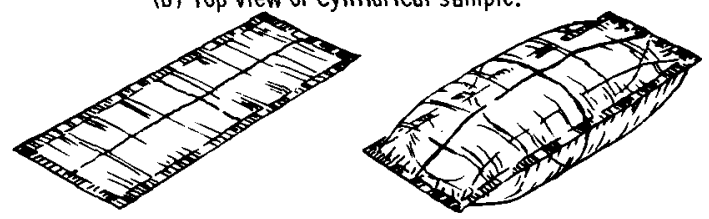

(c) View of 4- by 11 -inch $(10.1-$ by $27.9-\mathrm{cm})$ flat sample.

Figure 11. - Flat and cylindrical film samples before and after immersion in liquid hydrogen. Film, 10 plies of $1 / 4-\mathrm{mil}$ (0.00063-cm) Mylar C film. 


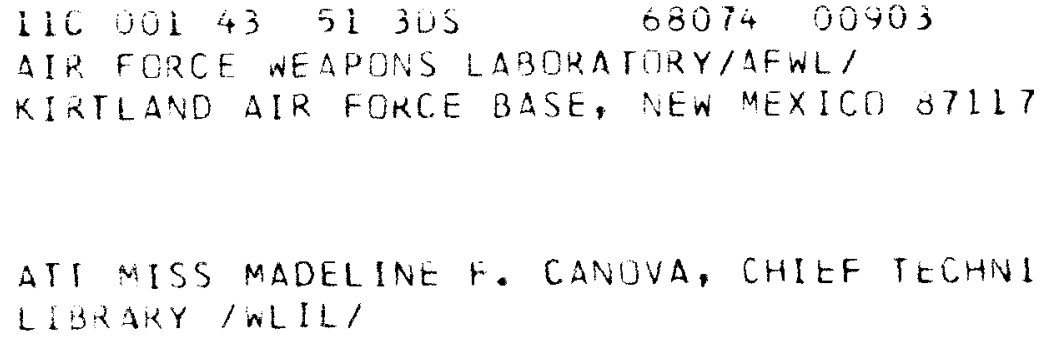

"The aeronautical and space activities of the United States shall be conducted so as to contribute ... to the expansion of buman knowledge of phenomena in the atmosphere and space. The Administration shall provide for the widest practicable and appropriate dissemination of information concerning its activities and the results thereof."

-National Afronautes and Spact act of 1958

\section{NASA SCIENTIFIC AND TECHNICAL PUBLICATIONS}

TECHNICAL REPORTS: Scientific and technical information considered important, complete, and a lasting contribution to existing knowiehe

TECHNICAL NOTES: Information less broad in scope but nevertheless of importance as a contribution to existing knowledge.

TECHNICAL MEMORANDUMS: Information receiving limited distribution because of preliminary data, security classification, or other teasons.

CONTRACTOR REPORTS: Scientific and technical information generated

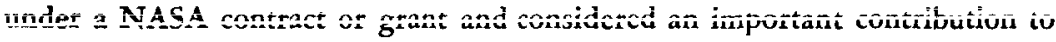
existing knowledge.

TECHNICAL TRANSLATIONS: Information published in a foreign language considered to metit NASA distribution in English.

SPECIAL PUBLICATIONS: Information derived from or of value to NASA activities. Publications include conference proceedings, monographs, data compilations, handbooks, sourcebooks, and special bibliographies.

TECHNOLOGY UTILIZATION PUBLICATIONS: Information on technology used by NASA that may be of particular interest in commercial and other non-aerospace applications. Publications include Tech Briefs, Technology Utilization Reports and Notes, and Technology Surveys.

Details on the availability of these publications may be obtained from:

SCIENTIFIC AND TECHNICAL INFORMATION DIVISION

NATIONAL AERONAUTICS AND SPACE ADMINISTRATION

Wrashingion, D.C. 200540 